\title{
ORIGINAL
}

\section{O PROGRAMA DE MERENDA ESCOLAR DE CAMPINAS: ANÁLISE DO ALCANCE E LIMITAÇÕES DO ABASTECIMENTO REGIONAL'}

\section{THE SCHOOL MEALS PROGRAM IN CAMPINAS: ANALYSIS OF THE REGIONAL SUPPLYING}

\author{
Rodrigo Pinheiro de Toledo VIANNA ${ }^{2}$ \\ Mauro José Andrade TERESO ${ }^{3}$
}

RESUMO

\begin{abstract}
O objetivo principal do trabalho foi avaliar as condições para o cumprimento da meta estabelecida pelo Programa Nacional de Merenda Escolar que recomenda o abastecimento local do Programa, de acordo com a política de descentralização do Governo Federal. Foram utilizados quatro critérios para avaliar a disponibilidade de produtos alimentícios para o programa: o nível, o volume e a composição da produção; as condições de transporte, estocagem e conservação; a comercialização; e os sistemas de distribuição de alimentos. Os resultados das análises indicaram um quadro bastante favorável devido à grande variedade de produtos agrícolas, existência de importantes eixos rodoviários e entrepostos de distribuição de alimentos, grande capacidade armazenadora e alta concentração de unidades agroindustriais na região, além da presença, no município, de uma ampla rede varejista de comercialização. As considerações deste trabalho visaram apresentar alternativas para os administradores públicos, auxiliando-os nos seus processos decisórios.
\end{abstract}

Termos de indexação: alimentação escolar, abastecimento de alimentos, política de alimentos.

ABSTRACT

The main objective of this work was to evaluate the conditions for the regional supply of the school meals program, according to its Federal Policy. The methodology applied in the city of Campinas, Brazil, measures the food availability in relation to level, volume and horticultural production, main roads, warehouses, commercialization, food industries and marketing net in the city. The results of these analyses showed the great possibility of managing to do the regional supply of the school meals program. The conclusions of this work aim at contributing important information to the decision-makers involved in the school meals program, presenting alternatives, which represent possible gains in the quality of the service offered to the schoolchildren.

Index terms: school feeding, food supply, food policy.

\section{INTRODUÇÃO}

A descentralização do Programa Nacional de Alimentação Escolar (PNAE), iniciada em 1993, transferiu para o município a responsabilidade da gestão da merenda escolar, que prevê entre outras competências, a prestação de contas da utilização dos recursos ao Governo Federal, o principal financiador do programa. Com esta medida

\footnotetext{
(1) Baseado na dissertação de mestrado O Programa de merenda escolar: subsídios para o planejamento do programa em Campinas, apresentada à Faculdade de Engenharia Agrícola, Universidade Estadual de Campinas, 1997.

(2) Departamento de Medicina Preventiva e Social, Universidade Estadual de Campinas, Cidade Universitária Zeferino Vaz, Caixa Postal 6111, 13083-970, Campinas, SP, Brasil. Correspondência para/Correspondence to: R.P.T.VIANNA. E-mail: vianna@unicamp.br

(3) Área de Planejamento e Desenvolvimento Rural, Faculdade de Engenharia Agrícola, Universidade Estadual de Campinas.
} 
buscou-se simplificar a estrutura burocrática no nível central, além de otimizar a utilização dos recursos financeiros. Cabe notar que entre as metas e diretrizes da política de descentralização, destaca-se o abastecimento do programa com os recursos locais, em função da capacidade de produção local, regional ou estadual e dos mecanismos de distribuição de alimentos do município (Fundação..., 1994).

O Estado de São Paulo pioneiramente implantou, no ano de 1983, um "Programa de Municipalização da Merenda Escolar", e a partir desta experiência a Secretaria Estadual de Educação realizou uma avaliação onde constatou um ganho de qualidade do Programa, aumentando significativamente o volume de alimentos servidos aos escolares, havendo até a inclusão no cardápio de carne bovina, carne suína, frango, peixe, ovos, leite fresco e frutas (Gonçalves, 1993). À esta política somavam-se projetos alternativos de produção de alimentos como hortas comunitárias, integração de pequenos produtores rurais, serviços municipais de apoio ao desenvolvimento rural, padarias municipais, cozinhas pilotos, produção de leite fluido, projetos de apicultura, piscicultura e cunicultura e mini-usinas de produção de extrato hidrossolúvel de soja. Com a municipalização pretendiase corrigir problemas de logística do programa, bem como simplificar os procedimentos de aquisição dos produtos. As compras seriam executadas diretamente pelas Prefeituras, para atendimento de um contingente menor de escolares e existiria a possibilidade de utilizar mecanismos licitatórios mais simples, como convite ou compra direta. Esta forma de fazer as aquisições substituiria as compras centralizadas, de grandes quantidades, que requerem procedimentos de licitação mais complexos (Secretaria..., 1986).

Tendo em vista a meta do abastecimento regional do programa de merenda, a análise da operacionalização deste, em nível municipal, deve levar em consideração as condições de disponibilidade de alimentos na região. Em cada caso, as dificuldades operacionais dependerão das características regionais e de infra-estrutura pública, variando desde situações onde as condições de abastecimento são plenamente suficientes, até situações onde tais condições inexistam.

Em Campinas, município de grande porte do Estado de São Paulo, o programa vem atendendo os escolares nos 200 dias do ano letivo, entretanto a Prefeitura tem sérios problemas de natureza administrativa, operacional e de cumprimento das metas da política de descentralização do Governo Federal. A Coordenadoria de Nutrição, órgão gestor do programa vinculado à Secretaria da Educação, opera com insuficiência de recursos humanos, problemas de capacitação da sua equipe, dificuldade para a reunião do Conselho de Alimentação Escolar e investe quase que a totalidade de seu tempo nas atividades de compra, controle de estoque e abastecimento de produtos às escolas. Na maioria dos dias da semana a merenda servida nas escolas não alcança $15 \%$ das recomendações de energia e proteína das crianças ${ }^{4}$ e a deficiência é ainda maior quando se observa o fornecimento de micronutrientes como cálcio, ferro, vitaminas A, C, Tiamina e Riboflavina. Ainda é alta a presença de produtos "formulados" 5 nos cardápios servidos na merenda, ao contrário do objetivo de educação alimentar apregoado. O estímulo à produção local de alimentos, ao comércio ou à indústria, são metas pertencentes ao discurso e não à ação (Vianna, 1997).

O objetivo específico deste trabalho foi avaliar as condições para o cumprimento daquelas metas da municipalização, no que diz respeito ao abastecimento local do programa e ao atendimento de $15 \%$ das recomendações nutricionais dos escolares, sugerindo alternativas aos administradores públicos para auxiliar seus processos decisórios.

\section{MATERIAL E MÉTODOS}

Para avaliar a viabilidade do abastecimento municipal do programa de merenda em Campinas utilizou-se quatro critérios que, segundo Chonchol (1989) definem, nas economias mercantis, a disponibilidade de produtos alimentícios para o consumo. São eles:

a) o nível de disponibilidade, o volume e a composição da produção alimentar do território no qual vive uma população determinada;

b) as condições de transporte, estocagem, e de conservação dessa produção;

c) a importância das exportações e das importações de produtos alimentícios para esse país ou para essa região, e

d) o funcionamento e a eficiência dos sistemas de distribuição de alimentos. critérios.

Os itens a seguir, descrevem cada um destes quatro

\section{O nível, o volume e a composição da produção alimentar da Região de Campinas}

O nível de disponibilidade alimentar depende do volume e da composição da produção de alimentos.

\footnotetext{
(4) A Lei n. 8.913, de 12 de julho de 1994, que dispõe sobre a descentralização da merenda escolar, não estabelece metas/parâmetros nutricionais do programa, ficando esta responsabilidade a cargo de um nutricionista capacitado em acordo com o Conselho de Alimentação Escolar. A referência a 15\% das necessidades diárias de energia e proteína advém das normas estabelecidas em 1983, quando da criação da Fundação de Assistência ao Estudante (FAE). Cabe ainda destacar que nunca foram estabelecidas, legalmente, normas para o oferecimento de micronutrientes.

(5) Produto obtido pela mistura de ingredientes tais como cereais e vegetais desidratados, farinhas de cereais, leite em pó, condimentos, massas alimentícias, extrato de carne e outros (NTA 77, legislação complementar do código sanitário de 22 de setembro de 1978, decreto n. 12.486 de 20 de outubro de 1978 , Governo do Estado de São Paulo). Produtos constituídos por misturas em pós de vários ingredientes, destinados a preparar alimentos diversos pela complementação com água, leite ou outro produto alimentício, submetido ou não a posterior cozimento (NTA 79, idem).
} 
Quanto maior o volume e a variedade da produção de uma determinada região, maior será a disponibilidade de alimentos (Chonchol, 1989).

O município de Campinas integra a Divisão Regional Agrícola (DIRA) de Campinas. É a maior e, juntamente com a de São José dos Campos, constitui uma das mais urbanizadas das 13 DIRAs do Estado de São Paulo, que são administradas pela Secretaria Estadual de Agricultura e Abastecimento.

Como pode ser observado, (Tabela 1), devido ao fato da região metropolitana de São Paulo fazer parte desta DIRA, em apenas 103 (quase um sexto dos municípios do Estado) concentra-se mais de $50 \%$ da população do Estado. Os grandes centros urbanos existentes influenciam fortemente a produção agrícola desta região, absorvendo a produção tanto para o consumo local como para a exportação.

Esta região ocupa desde o início do século a posição mais destacada na agropecuária paulista, notabilizada pela diversidade de suas explorações rurais (Junqueira et al., 1994).

Os dados da Tabela 2 refletem a importância relativa da DIRA de Campinas em termos da produção de alimentos, sendo a região uma das principais produtoras de hortícolas no Estado e destacando-se, também, na fruticultura. Essa DIRA tem participação relativa no Estado de São Paulo em torno de $10 \%$ da produção de alimentos básicos, $21 \%$ de fruticultura e $27 \%$ de horticultura. Isto garante a variedade dos alimentos disponíveis na região e assegura, a priori, o acesso do programa a todos os produtos que poderiam compor um cardápio para a merenda de acordo com o consumo local, conforme as metas da política de descentralização do programa de alimentação escolar.

Para estimar o volume da produção de alimentos da região de Campinas não foi utilizada a divisão por DIRAs, devido à influência da região metropolitana de São Paulo, mas a classificação da Fundação do Instituto Brasileiro de Geografia e Estatística (IBGE), que define a região de Campinas em uma microrregião homogênea, composta por 13 municípios. Além de Campinas, são eles: Americana, Cosmópolis, Elias Fausto, Indaiatuba, Jaguariúna, Monte Mor, Nova Odessa, Paulínia, Pedreira, Santa Bárbara D’Oeste, Sumaré, Valinhos e Vinhedo.
Adotando-se esta divisão para a Região de Campinas, a Tabela 3 indica entre as principais lavouras temporárias e culturas permanentes do Estado de São Paulo, a área plantada, a área destinada à colheita e as quantidades produzidas por ano de vários produtos de interesse para a análise do abastecimento do programa de merenda escolar (Instituto..., 1990).

As quantidades produzidas, tomando-se como base o ano de 1990 e considerando que não houveram mudanças significativas no perfil da produção, apresentam o volume da produção agrícola local.

\section{Condições de transporte, estocagem e conservação da produção}

O processo de transformação da agricultura na região de Campinas foi beneficiado pela facilidade dos grandes eixos rodoviários e a proximidade de grandes centros distribuidores de alimentos como a Companhia de Entrepostos e Armazéns Gerais de São Paulo (CEAGESP), na Grande São Paulo, e da Central de Abastecimento e Serviços Auxiliares (CEASA) de Campinas.

O Estado de São Paulo, segundo o Cadastro de Unidades Armazenadoras de 1987, conta com uma capacidade estática de armazenagem de 13 milhões de toneladas, atendendo quantitativamente a produção anual agrícola do Estado, que gira em torno de 8,5 milhões de toneladas. Apesar da capacidade de armazenagem do Estado ser suficiente, as condições da maioria dos armazéns é de baixa qualidade, destinados para guarda de produtos ensacados. A DIRA de Campinas responde por um quarto da capacidade de armazenamento estadual instalada (Nogueira JR., 1991).

Impulsionado pela agricultura, a região viabilizou um contínuo processo de industrialização centrado na agroindústria, com intenso processo de integração vertical envolvendo grupos privados e cooperativas. Como é indicado na Tabela 4, as agroindústrias alimentares constituem o maior número absoluto de unidades instaladas na região e em porcentagem representam 43,72\% do Estado de São Paulo.

Tabela 1. Dados demográficos da DIRA de Campinas e do Estado.

\begin{tabular}{|c|c|c|c|c|c|}
\hline \multirow[b]{2}{*}{ Região } & \multirow{2}{*}{$\begin{array}{c}\mathrm{n} \\
\text { municípios }^{*}\end{array}$} & \multicolumn{3}{|c|}{ População residente } & \multirow{2}{*}{$\begin{array}{c}\text { Taxa de } \\
\text { urbanização (\%) }\end{array}$} \\
\hline & & Total & Urbana & Rural & \\
\hline DIRA Campinas & 103 & 15893605 & 15204625 & 688980 & 95,67 \\
\hline Outras DIRA & 522 & 15652868 & 14068302 & 1584566 & 89,88 \\
\hline Total do Estado & 625 & 31546473 & 29272927 & 2273546 & 92,79 \\
\hline
\end{tabular}


Tabela 2. Área cultivada e natural da DIRA de Campinas e do Estado de São Paulo, 1991/92.

\begin{tabular}{|c|c|c|c|c|c|}
\hline \multirow[b]{2}{*}{ Culturas } & \multicolumn{3}{|c|}{ DIRA de Campinas } & \multicolumn{2}{|c|}{ Total Estado } \\
\hline & $\begin{array}{c}\text { Área } \\
\text { (mil habitantes) }\end{array}$ & $\begin{array}{c}\% \\
(1)\end{array}$ & $\begin{array}{c}\% \\
(2)\end{array}$ & $\begin{array}{c}\text { Área } \\
\text { (mil habitantes) }\end{array}$ & $\%$ \\
\hline Culturas anuais & 219,0 & 9,9 & 8,0 & 2724,9 & 13,3 \\
\hline Arroz, feijão e mandioca de mesa & 51,0 & 2,3 & 9,5 & 537,6 & 2,6 \\
\hline Milho, soja, trigo e mandioca industrial & 141,5 & 6,4 & 7,8 & 1822,8 & 8,9 \\
\hline Outras & 26,5 & 1,2 & 7,3 & 364,5 & 1,8 \\
\hline Culturas perenes & 525,1 & 23,8 & 19,2 & 2734,1 & 13,1 \\
\hline Cana & 433,9 & 19,6 & 18,8 & 2311,9 & 11,1 \\
\hline Café & 90,1 & 4,1 & 24,8 & 364,1 & 1,7 \\
\hline Outras, exceto fruticultura & 1,1 & 0,1 & 1,9 & 58,1 & 0,3 \\
\hline Fruticultura & 203,0 & 9,2 & 21,2 & 959,1 & 4,6 \\
\hline Citricultura & 190,1 & 8,6 & 22,9 & 831,8 & 4,0 \\
\hline Outras frutas & 12,9 & 0,6 & 10,2 & 127,3 & 0,6 \\
\hline Horticultura & 25,4 & 1,1 & 27,1 & 93,9 & 0,4 \\
\hline Pastagem & 894,9 & 40,6 & 8,4 & 10668,5 & 51,4 \\
\hline Reflorestamento & 142,6 & 6,5 & 14,7 & 967,2 & 4,7 \\
\hline Vegetação natural & 196,4 & 8,9 & 7,5 & 2618,1 & 12,5 \\
\hline Total & 2206,4 & 100,0 & 10,6 & 20765,8 & 100,0 \\
\hline
\end{tabular}

Do ponto de vista da oferta de produtos industrializados para a região, é possível afirmar que a DIRA, ou até a microrregião de Campinas, é auto-suficiente em qualidade e quantidade de produtos para atender sua população, sendo ainda uma importante exportadora para todo o país.

Estas considerações indicam o alto potencial da região em função da sua infra-estrutura, garantindo as melhores condições, no Estado de São Paulo, de transporte, estocagem, transformação e conservação da produção agrícola local e regional, favorecendo o aproveitamento destes produtos nos programas de alimentação institucional como é o caso da merenda escolar.

\section{A importância da comercialização de produtos alimentícios, o funcionamento e a eficiência dos sistemas de distribuição de alimentos}

Por se tratar de uma região cosmopolita, a comercialização de alimentos assume uma importância muito grande na movimentação de bens e recursos, tanto na região como no país. Na parte norte do município, localiza-se a CEASA Campinas, principal entreposto de comercialização de produtos hortifrutícolas da região e o segundo maior do Estado (Tabela 5).

A comparação entre a produção da microrregião de 1990 e a movimentação de produtos na CEASA de 1994 indica, de forma aproximada, a representatividade da produção local frente o montante de produtos que circulam neste equipamento de abastecimento (Escola..., 1992).

Os valores obtidos para os 12 produtos apresentados na Tabela 6 , mostram que eles se diferenciam em três categorias: produzidos e comercializados in natura na região; principalmente produzidos na região; e principalmente comercializados in natura na região. Os primeiros são aqueles que alcançaram valores próximos da unidade, ou seja, goiaba, manga e poncã. Os segundos são os que obtiveram valores mais próximos de zero: laranja e milho, indicando que são produzidos em quantidades muito maiores que aquelas comercializadas pela CEASA e, neste caso, atendem outras demandas como a agroindústria local. O tomate, por sua vez, se posiciona em um nível intermediário entre estas duas categorias. Os demais produtos, batata-doce, batata, cebola, banana, maçã e mamão (com atenção especial à 
cebola e ao mamão que alcançam valores 234 e 1 480, respectivamente), são provenientes de outras regiões, uma vez que a CEASA comercializa quantidades muito superiores às produzidas na região.

Os produtos básicos tradicionais, como o arroz e o feijão, não são comercializados em grande quantidade na CEASA de Campinas, sendo adquiridos pelos principais equipamentos de abastecimento do município em outros atacadistas, como o Entreposto Terminal de São Paulo ou a Bolsa de Cereais de São Paulo.

Devido à falta de informações sobre a produção e/ou comercialização, na microrregião, de arroz, feijão, pão, macarrão e dos produtos de origem animal, foram utilizados os dados de consumo per capita/dia para se estimar as quantidades aproximadas destes produtos que a população teve acesso. Assim, os valores de consumo de carne bovina, carne de frango, carne de porco, ovos, leite, pão, macarrão, arroz e feijão em Campinas (Núcleo...,
1995) corrigidos para o total populacional da microrregião (Instituto..., 1994) aproxima a quantidade movimentada destes produtos por ano, através de diversos equipamentos de abastecimento, sem o detalhamento relativo aos mecanismos de distribuição destes produtos.

Somente os itens descritos na Tabela 7 somam quase 350 mil toneladas/ano de alimentos comercializados na microrregião, através de diversos equipamentos, atacadistas e/ou varejistas. A partir deste dado pode-se afirmar que a distribuição de alimentos em Campinas é eficaz, contando com uma enorme rede varejista, além dos grandes atacadistas, como a CEASA e o MACRO. De acordo com os dados da Secretaria Estadual da Fazenda sobre os contribuintes do Imposto de Circulação de Mercadorias e Serviços (ICMS) do ano 1996, tem-se entre os principais equipamentos de abastecimento de alimentos: 5 hipermercados, 80 supermercados, 106 açougues, 139 mercearias e quitandas e 177 padarias.

Tabela 3. Área cultivada e quantidade produzida por ano, na microrregião de Campinas, dos produtos básicos de consumo. Estado de São Paulo, 1990.

Culturas

Cultura temporári
Arroz (em casca)
Batata-doce
Batata-inglesa
Cebola
Feijão (em grão)
Mandioca
Milho (em grão)
Tomate
Trigo (em grão)

Cultura permanente

\begin{tabular}{l} 
Abacate \\
Banana ${ }^{(1)}$ \\
Caqui \\
Figo \\
Goiaba \\
Laranja \\
Limão \\
Maçã \\
Mamão \\
Manga \\
Pêra \\
Pêssego \\
Tangerina \\
Uva (2) \\
\hline (1) Quantidade em mil cachos \\
(2) Quantidade em toneladas \\
Fonte: Instituto... (1990).
\end{tabular}

Área plantada

(ha)

Quantidade produzida por ano

(t)

$\begin{array}{cc}275 & 3671 \\ 85 & 1030 \\ 605 & 15909 \\ 9 & 68 \\ 1985 & 2052 \\ 1086 & 17994 \\ 7950 & 24054 \\ 1536 & 69275 \\ 85 & 132\end{array}$

Área destinada à colheita

(ha)

886

38

$1040 \quad 240471$

$256 \quad 16003$

$9157 \quad 864550$

$696 \quad 70898$

$13-690$

1230

$\begin{array}{ll}431 & 10927\end{array}$

1250

$70 \quad 5901$

$667 \quad 56497$

$1562 \quad 13243$ 
Tabela 4. Número e porcentagem de agroindústrias, por grupo de atividade, na DIRA de Campinas e no total do Estado, 1989.

\begin{tabular}{lccc}
\hline Atividade & DIRA de Campinas & \% do total & Estado de São Paulo \\
\hline Borracha & 75 & 63,56 & 118 \\
Couro & 35 & 17,07 & 205 \\
Química & 158 & 49,22 & 321 \\
Têxtil & 144 & 64,86 & 222 \\
Alimentar & 2114 & 43,72 & 4835 \\
Bebida & 385 & 40,02 & 962 \\
Fumo & 5 & 45,45 & 11 \\
\hline Total & 2916 & 43,69 & 6674 \\
\hline
\end{tabular}

Fonte: Junqueira et al., 1994.

Estes números indicam uma situação favorável para a elaboração de alternativas ao modelo centralizado de compras adotado para o programa de merenda em Campinas, visando o abastecimento descentralizado, respeitando, na prática de operacionalização do programa, os princípios da descentralização.

\section{Avaliação da disponibilidade de alimentos para o abastecimento do Programa em Campinas}

A partir dos dados da produção agrícola, da comercialização de hortifrutícolas na CEASA e da média do consumo dos principais itens básicos, pode-se estimar a quantidade de alimento disponível na microrregião de Campinas. Para avaliar a importância do abastecimento do programa a partir destes produtos, transformou-se os dados da análise - a demanda do programa de merenda em Campinas e os alimentos disponíveis na microrregião - em uma unidade comum: nutrientes.

A demanda do programa foi estimada multiplicando-se as recomendações de energia e proteína do programa, e 15\% das recomendações diárias (Vannucchi et al., 1990) de uma "criança-referência" de 10 anos $^{6}$ para cálcio, fósforo, ferro, retinol, vitamina Tiamina, Riboflavina e vitamina $C$, pelo número de alunos atendidos pelo programa na rede pública de ensino de Campinas. O valor obtido, multiplicado pelo total de dias letivos (200 dias), forneceu a demanda nutrientes anuais do público alvo.
Para a estimativa da quantidade de nutrientes disponíveis, transformou-se as quantidades de alimentos da região ${ }^{7}$, mil frutos, mil cachos e toneladas, em quilograma de parte comestível (Luna, 1995) e, em seguida, com o auxílio da Tabela de composição química dos alimentos da FIBGE (Instituto..., 1977) calculou-se os nutrientes totais de cada produto.

Para avaliar o impacto da utilização dos alimentos da região para o abastecimento do programa de merenda em Campinas, estimou-se a porcentagem dos alimentos disponíveis na região necessária para atender o requerimento nutricional do programa, ou seja, o produto da porcentagem da população atendida pelo programa em Campinas (138 199 alunos, que é igual a 7,8\% do total populacional da microrregião) com a recomendação legal (15,0\% das necessidades nutricionais diárias do público atendido). O valor encontrado foi de 1,17\%.

Na Tabela 8, a relação entre os valores calculados (A/B) é menor que $1,17 \%$ para todos os nutrientes, com exceção do cálcio que atinge $1,49 \%^{8}$. Esta relação poderia ainda ser menor se fossem incluídos nas análises alguns produtos industrializados, como doces, queijos, achocolatados e embutidos, que também têm um alto potencial para serem incorporados no programa de merenda, pois fazem parte do consumo alimentar da população de Campinas (Núcleo..., 1995), e são fontes ricas em energia e proteínas e, no caso do queijo, em cálcio.

\footnotetext{
(6) Para este cálculo optou-se pela utilização de uma "criança-referência" de 10 anos (o público alvo da merenda escolar pertence à faixa de 7 a 14 anos) porque considerouse desnecessário encontrar um valor com maior grau de precisão para a somatória da recomendação nutricional de todos os alunos deste programa uma vez que diversos outros fatores influenciam na necessidade real de nutrientes desta população, tomando-se como princípio o atendimento de uma porcentagem das suas necessidades diárias, como por exemplo atividade física e estado de saúde e, também, porque estávamos buscando uma estimativa deste valor. A justificativa desta opção pode ser corroborada com a comparação entre a recomendação da "criança-referência" com a média ponderada, por faixa etária, das recomendações das crianças matriculadas em 36 escolas públicas da S.A.R. Norte do município de Campinas, onde encontrou-se uma diferença de: 0,1\% para energia; 2,2\% para proteína; 0,1\% para retinol; 1,0\% para vitamina C; 4,5\% para vitamina Tiamina; 1,7\% para vitamina Riboflavina; 0,3\% para ferro; 0,1\% para cálcio; e 13,5\% para fósforo.

(7) (Total produzido + Total comercializado na CEASA + Total consumido segundo as estimativas de consumo), descontando-se as quantidades produzidas do total comercializado e do consumido, para evitar a duplicação de dados.

(8) Este resultado pode estar sendo influenciado pela fonte de dados do consumo per capita/dia médio utilizada neste estudo, que diagnosticou um consumo deficiente em cálcio na população de Campinas (Núcleo..., 1995).
} 
Tabela 5. Quantidadecomercializada, das principais verduras, legumes e frutas na CEASA Campinas, 1994.

\begin{tabular}{|c|c|}
\hline Nome & Toneladas/Ano \\
\hline \multicolumn{2}{|l|}{ Verduras } \\
\hline Acelga & 1511,4 \\
\hline Alface crespa & 1329,3 \\
\hline Alface lisa & 2941,1 \\
\hline Couve & 377,2 \\
\hline Espinafre & 293,7 \\
\hline Repolho & 11581,9 \\
\hline \multicolumn{2}{|l|}{ Legumes } \\
\hline Batata lisa & 5985,4 \\
\hline Batata comum & 27865,5 \\
\hline Batata-doce & 3107,2 \\
\hline Berinjela & 3824,4 \\
\hline Beterraba & 4849,6 \\
\hline Abobrinha italiana & 524,6 \\
\hline Abobrinha & 5250,7 \\
\hline Cebola & 15930,1 \\
\hline Cenoura & 13490,6 \\
\hline Chuchu & 7888,9 \\
\hline Mandioquinha & 3236,2 \\
\hline Inhame & 213,3 \\
\hline Milho verde & 3723,3 \\
\hline Pepino caipira & 7455,9 \\
\hline Pepino japonês & 909,9 \\
\hline Tomate Sta. Cruz & 41802,6 \\
\hline Vagem & 4423,1 \\
\hline \multicolumn{2}{|l|}{ Frutas } \\
\hline Banana-nanica & 29541,9 \\
\hline Banana-maçã & 7150,7 \\
\hline Banana-prata & 3105,2 \\
\hline Goiaba & 2640,7 \\
\hline Laranja-da-baía & 2583,3 \\
\hline Laranja-lima & 3194,4 \\
\hline Laranja-pêra & 59214,6 \\
\hline Poncã & 9142,2 \\
\hline Maçã & 19577,8 \\
\hline Mamão formosa & 17800,9 \\
\hline Mamão havaí & 10842,0 \\
\hline Manga haden & 8274,2 \\
\hline Manga espada & 385,9 \\
\hline
\end{tabular}

Fonte: Boletins da CEASA Campinas, 1994 (dados organizados pelos autores.

De acordo com os requerimentos nutricionais do programa e com as metas da municipalização, este resultado permite afirmar que todo o abastecimento do programa de merenda do município pode ser feito com alimentos provenientes ou que já circulam na própria microrregião. É evidente que existe quantidade suficiente
Tabela 6. Relação estimada entre o total comercializado na CEASA Campinas e a produção agrícola de hortifrutículos da região.

\begin{tabular}{lc}
\hline Produto & Comercialização/Produção \\
\hline Batata-doce & 3,0 \\
Batata & 2,1 \\
Cebola & 234,2 \\
Milho verde & 0,1 \\
Tomate & 0,6 \\
Banana & 22,4 \\
Goiaba & 0,7 \\
Laranja & 0,4 \\
Poncã & 1,1 \\
Maçã & 168,8 \\
Mamão & 1480,2 \\
Manga & 0,9 \\
\hline
\end{tabular}

de gêneros alimentícios que pode ser incorporada ao programa. Em outras palavras, o abastecimento do programa em Campinas não causaria maiores impactos no abastecimento da região se optar por se servir exclusivamente dos seus produtos, que já circulam e/ou são produzidos no seu sistema agro-alimentar.

\section{Considerações sobre o abastecimento do programa}

Para aumentar a eficácia da aquisição e distribuição da merenda, seria necessário analisar tanto a estrutura operacional do programa como os aspectos legais que envolvem as compras públicas, buscando-se elaborar novos mecanismos que aproveitem as potencialidades do município como sua própria rede de abastecimento.

A transformação dos mecanismos de abastecimento possibilitaria aos administradores do programa maior flexibilidade para suas atividades, ajudando-os a solucionar problemas de natureza administrativa, particularmente os relacionados à aquisição de alimentos. Isto permitiria à Coordenadoria de Nutrição assumir na prática o papel de gestora, responsável pela operacionalização da merenda escolar, tendo por base a formulação da política de alimentação aos escolares.

A integração dos elementos existentes no municípios, tais como produtores locais, comércio e indústria, permitiriam à Prefeitura um maior grau de liberdade para as decisões, buscando otimizar os recursos existentes na formulação de cardápios, de acordo com as necessidades das crianças e com condições de preparo em cada escolas, em melhores alternativas de preços de gêneros alimentícios e na participação da população no programa. Esta nova dinâmica de operacionalização, permitiria considerar, por exemplo, as diferenças da população alvo. 
Tabela 7. Consumo per capita e estimativa em toneladas da movimentação anual de produtos básicos e de origem animal na microrregião de Campinas, 1994.

\begin{tabular}{|c|c|c|}
\hline Produto & $\begin{array}{l}\text { Quantidade per capita/dia } \\
\text { (g) }\end{array}$ & $\begin{array}{l}\text { Quantidade mínima disponível na } \\
\text { microrregião/ano }(\mathrm{t})\end{array}$ \\
\hline Arroz & 109,1 & 70532,9 \\
\hline Feijão & 36,8 & 23803,6 \\
\hline Pão & 50,0 & 32325,7 \\
\hline Macarrão & 21,9 & 14197,4 \\
\hline Carne bovina & 43,5 & 28123,4 \\
\hline Carne bovina com osso & 7,5 & 4874,7 \\
\hline Frango & 42,2 & 27282,9 \\
\hline Carne suína & 4,3 & 2780,0 \\
\hline Carne suína com osso & 4,1 & 2650,7 \\
\hline Ovos & 30,4 & 19564,0 \\
\hline Leite & 187,3 & 121092,1 \\
\hline
\end{tabular}

Fonte: Núcleo... (1995) (dados organizados pelos autores).

Tabela 8. Relação entre a necessidade de nutrientes para o atendimento do programa de merenda escolar e nutrientes dos alimentos disponíveis na microrregião de Campinas.

\begin{tabular}{|c|c|c|c|}
\hline Nutriente & $\begin{array}{l}\text { Necessidade de nutrientes para o programa } \\
\text { de merenda } \\
\text { (A) }\end{array}$ & $\begin{array}{l}\text { Quantidade de nutrientes disponíveis na } \\
\text { microrregião } \\
\text { (B) }\end{array}$ & $\begin{array}{c}\mathrm{A} / \mathrm{B} \\
\mathrm{x} 100 \\
(\%)\end{array}$ \\
\hline Energia (kcal) & $8,29 \cdot 10^{9}$ & $8,74 \cdot 10^{11}$ & 0,95 \\
\hline Proteína (g) & $2,21 \cdot 10^{8}$ & $3,61 \cdot 10^{10}$ & 0,61 \\
\hline Cálcio (mg) & $4,35 \cdot 10^{9}$ & $2,93 \cdot 10^{11}$ & 1,49 \\
\hline Fósforo (mg) & $4,98 \cdot 10^{9}$ & $5,63 \cdot 10^{11}$ & 0,88 \\
\hline Ferro (mg) & $5,80 \cdot 10^{7}$ & $8,23 \cdot 10^{9}$ & 0,71 \\
\hline Retinol $(\mu \mathrm{g})$ & $2,61 \cdot 10^{9}$ & $2,38 \cdot 10^{11}$ & 1,10 \\
\hline Tiamina (mg) & $3,32 \cdot 10^{6}$ & $7,59 \cdot 10^{8}$ & 0,44 \\
\hline Riboflavina (mg) & $5,39 \cdot 10^{6}$ & $6,42 \cdot 10^{8}$ & 0,84 \\
\hline Vitamina C (mg) & $2,16 \cdot 10^{8}$ & $1,51 \cdot 10^{11}$ & 0,14 \\
\hline
\end{tabular}

\section{CONCLUSÃO}

Em Campinas, o aproveitamento dos recursos do município e região, o abastecimento municipal de maneira integrada com os programas institucionais, a efetiva implementação de cardápios variados de acordo com a regionalidade, apontam para um quadro bastante favorável de melhora qualitativa do programa de merenda. Os dados apresentados neste trabalho, que corroboram para esta afirmação, são:

a) A região de Campinas, DIRA, do ponto de vista da variedade da produção agrícola, dispõe de praticamente todos os produtos possíveis de compor o cardápio da merenda, participando no Estado de São Paulo em 10\% da produção de alimentos básicos, $21 \%$ de fruticultura e $27 \%$ de horticultura. b) A região é beneficiada pela presença de grandes eixos rodoviários e da proximidade de importantes centros distribuidores de alimentos, como a CEAGESP e a CEASA-Campinas.

c) A DIRA de Campinas detém 25\% da capacidade armazenadora do Estado de São Paulo.

d) A região de Campinas é a região do Estado com a maior concentração de unidades agroindustriais, com destaque para a indústria de alimentos.

e) O município conta, além dos atacadistas MACRO e CEASA, com uma ampla rede de equipamentos varejistas de comercialização de alimentos.

f) $\mathrm{Na}$ microrregião de Campinas não existe atualmente limitação de oferta de produtos para serem utilizados no abastecimento do programa de merenda. Há 
disponibilidade suficiente de alimentos para abastecer a merenda sem provocar impacto no sistema de abastecimento de Campinas.

Assim é necessário rever a gestão do programa na Prefeitura, com a finalidade de agilizar sua administração e elaborar um planejamento visando atender as necessidades e preferências do público alvo. Caberia à Prefeitura promover a descentralização dos principais serviços e concomitantemente criar uma estrutura de controle.

A descentralização do PNAE possibilita a ampliação do exercício dos direitos e autonomia da gestão municipal, inclusive com maior controle dos recursos públicos. Assim, a alimentação escolar pode ser dinamizada se planejada, em conjunto, com várias áreas de atuação do poder público, como Abastecimento, Saúde, Promoção Social e Cultura, Esporte e Turismo, visando a aproximação do público dos administradores do programa e auxiliando o desenvolvimento social do indivíduo.

Finalmente, cabe reafirmar que a alimentação, além de ser um direito inalienável da população, deve estar associada aos preceitos de construção da cidadania, de modo que a escola e a alimentação escolar podem, e devem, ser uma atividade socializadora.

\section{REFERÊNCIAS BIBLIOGRÁFICAS}

CHONCHOL, J. O desafio alimentar: a fome no mundo. São Paulo : Marco Zero, 1989. 185p.

ESCOLA SUPERIOR DE AGRONOMIA LUIZ DE QUEIROZ. Abastecimento alimentar e ação pública municipal: o caso de Piracicaba. Piracicaba, 1992. 246p. Relatório de Pesquisa. (Convênio de Cooperação Técnica entre Escola Superior de Agricultura Luiz de Queiroz/USP e Prefeitura Municipal de Piracicaba).

FUNDAÇÃO DE ASSISTÊNCIA AO ESTUDANTE (Brasil). Diretoria de Apoio Alimentar e Nutricional. Descentralização do Programa
Nacional de Alimentação Escolar: Relatório de Atividades 93/94. Brasília: Ministério da Educação e do Desporto,1994. p.5-26.

GONÇALVES, F. (Relator). Auditoria operacional nos Programas de Suplementação Alimentar do Governo Federal: Relatório. Brasília : Tribunal de Contas da União, 1993. 236 p.

INSTITUTO BRASILEIRO DE GEOGRAFIA E ESTATÍSTICA. Estudo Nacional de Despesa Familiar. Tabelas de composição dos alimentos. Brasília, 1977. 201p.

INSTITUTO BRASILEIRO DE GEOGRAFIA E ESTATÍSTICA. Produção agrícola municipal. Culturas temporárias e permanentes. Região Sudeste. Rio de Janeiro, 1990. v.17: p.403-643.

INSTITUTO BRASILEIRO DE GEOGRAFIA E ESTATÍSTICA. Anuário estatístico do Brasil. Rio de Janeiro, 1994. p.2-35.

JUNQUEIRA, A.H., PEETZ, M.S., MANDELLI, C.S. A miséria e a fome no Estado de São Paulo. Conjuntura Alimentos, São Paulo, v.6, n.2, 1994. 86p. (Edição Especial).

LUNA, N.M.M. Técnica dietética: pesos e medidas em alimentos. Cuiabá : Editora da Universidade Federal do Mato Grosso, 1995. 20p.

NOGUEIRA JR., S. Agricultura e armazenagem em São Paulo. Informações Econômicas, São Paulo, v.21, n.6, p.9-12, 1991.

NÚCLEO DE ESTUDOS E PESQUISAS EM ALIMENTAÇÃO. Inquérito de consumo familiar de alimentos - Campinas, 1994. Campinas, 1995. 85p. (Relatório de Pesquisa; Mimeografado).

SECRETARIA DE ESTADO DA EDUCAÇÃO (SÃO PAULO). Departamento de Assistência ao Escolar. Municipalização da merenda escolar. São Paulo, 1986. 39p.

VANNUCCHI, H., MENEZES, E.W., CAMPANA, A.O., LAJOLO, F.M. Aplicação das recomendações nutricionais adaptadas à população brasileira. Cadernos de Nutrição SBAN, São Paulo, v.2, 1990. 156p.

VIANNA, R.P.T. O Programa de merenda escolar: subsídios para o planejamento do programa em Campinas. Campinas, 1997. 130p. Dissertação (Mestrado em Engenharia Agrícola) Faculdade de Engenharia Agrícola, Universidade Estadual de Campinas. 1997.

Recebido para publicação em 4 de junho de 1998 e aceito em 29 de abril de 1999. 